There are several tumor-like lesions and miscellaneous neoplasms of the rete testis. We present a case with adenomatous hyperplasia of the rete testis (AHRT). The patient was 24 years old with undescended testis and was referred to our hospital. There were no clinical or endocrine abnormalities. Cryptorchidism was unilateral and the other testis was normal. Right orchiectomy was performed and sent to the pathology laboratory for examination. Morphologic and immunohistochemistry findings confirmed the diagnosis of AHRT in this case. The patient's postoperative course continues uneventfully. AHRT is a rare lesion and can be confused with malignancy. It is incidentally detected in microscopic investigation. It may present as a very small lesion detected in microscopic examination or a solid-cystic mass lesion which is macroscopically evident. Clinical history, localization, histologic features and immunohistochemistry are criteria for differentiating these lesions.

We present this rare case for both surgeons and pathologists due to its importance as it can be confused with malignancy.

Key words: rete testis, hyperplasia, adenoma, testicular tumor.

Contemp Oncol (Pozn) 2013; 17 (5): 466-467 DOI: $10.5114 /$ wo.2013.37227

\section{Adenomatous hyperplasia of the rete testis: Not a true hyperplasia, just proliferation!}

Tumay Ozgur ${ }^{1}$, Mehmet Mustafa Akin ${ }^{1}$, Hasan Gokce' ${ }^{1}$, Mursel Davarci²

1Department of Pathology, Mustafa Kemal University School of Medicine, Antakya, Hatay, Turkey

2Department of Urology, Mustafa Kemal University School of Medicine, Antakya, Hatay, Turkey

\section{Introduction}

There are several tumor-like lesions and miscellaneous neoplasms of the rete testis. Adenomatous hyperplasia is a rare non-neoplastic rete epithelial proliferation [1]. It is incidentally found in autopsy specimens and surgical specimens with cryptorchidism and testicular germ cell tumor. The etiology and pathogenetic mechanism of adenomatous hyperplasia are not certain yet.

This non-neoplastic lesion is usually seated in the mediastinum and septal part of the rete testis [2]. It may present as a very small lesion detected in microscopic examination or a solid-cystic mass lesion which is macroscopically evident. In microscopic evaluation the lesion is made up of tubulopapillary and cribriform structures separated by scant stroma [3].

\section{Case presentation}

A 24-year-old man underwent surgery for a right undescended testis. Cryptorchidism was unilateral and the other testis was normal. There were no clinical or endocrine abnormalities.

The right orchiectomy specimen was sent to the Pathology Department for examination. The testis measured $4 \times 2.5 \times 2.2 \mathrm{~cm}$ in size and there was no tumoral lesion in gross examination. On the cut section close to the testis parenchyma, there was a gland like tubular structures. Some of these were in back-to-back position with little intervening stroma. The epithelium lining the tubules were cubic to low columnar cells (Fig. 1). The testicular parenchyma was comprised of seminiferous tubules that had Sertoli cells only and no spermatozoa (Fig. 2). EMA (Novocastra; 1/150, clone GP 1.4, Newcastle, United Kingdom) and pankeratin (Novocastra; 1/150, clone AE1/AE3, Newcastle, United Kingdom) immunohistochemical stains were performed for diagnosis. The luminal surface of tubular structures stained with EMA and cytoplasm with pankeratin. Morphologic and immunohistochemistry findings confirmed the diagnosis of AHRT in this case. The patient's postoperative course continues uneventfully.

\section{Discussion}

Adenomatous hyperplasia of the rete testis is a benign lesion which can appear at any time during life and was first described by Nistal et al. [2]. It is important to recognize tumor-like lesions of the rete testis to make an accurate differential diagnosis whether the lesion is benign or malign [4].

AHRT etiology is not well understood yet but there seem to be associated conditions such as cryptorchidism, some kidney diseases, and germ cell tumors. Our case was cryptorchid and seminiferous tubules near the lesion were lined by only Sertoli cells and had no spermatozoa. These findings were similar to Channer and Maclver's case [5]. The authors reported an adult case 


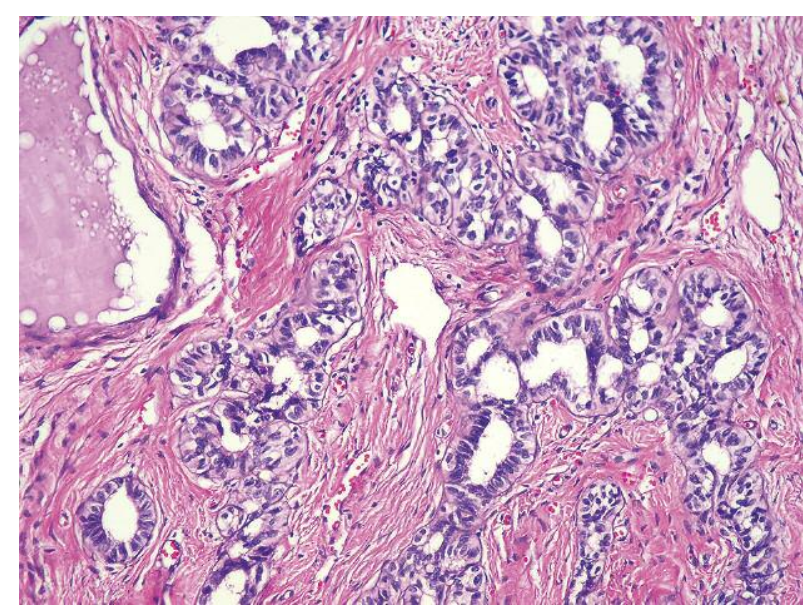

Fig. 1. Tubular structures with gland-like formation and pseudoinfiltrative pattern. HE, magnification 100x

with AHRT in unilateral testis with no luminal spermatozoa. There are different cases such as prostate adenocarcinoma or embryonal carcinoma together with AHRT in the literature $[6,7]$.

The true epithelial proliferation with gland-like or papillary proliferations replacing normal epithelium, continuous architecture of normal rete testis with adenomatous hyperplasia and lack of signs of malignancy are the proper diagnostic criteria for AHRT [2]. In our case the histomorphologic findings were similar to those reported in the literature.

The differential diagnosis should include adenoma, papillary adenoma, primary and metastatic adenocarcinoma and rete testis cystic transformations with epithelial metaplasia [2]. Clinical history, localization, histologic features and immunohistochemistry are criteria for differentiating these lesions. Complete surgical resection is the proposed therapy for AHRT cases and no report for recurrence has been identified [8].

In conclusion, adenomatous hyperplasia of the rete testis is a rare lesion that can be confused with malignancy and should be remembered in the differential diagnosis of rete testis lesions.

The authors declare no conflict of interests.

\section{References}

1. Amin MB. Selected other problematic testicular and paratesticular lesions: rete testis neoplasms and pseudotumors, mesothelial lesions and secondary tumors. Mod Pathol 2005; 18: 131-45.

2. Nistal M, Castillo MC, Regadera J, Garcia-Cabezas MA. Adenomatous hyperplasia of the rete testis.A review and report of new cases. Histol Histopathol 2003; 18: 741-52.

3. Juan R. Ackerman's Surgical Pathology. Mosby-Year Book, St. LouisMissouri 2004: 1457.

4. Jones EC, Murray SK, Young RH. Cysts and epithelial proliferations of the testicular collecting system (including rete testis). Semin Diagn pathol 2000; 17: 270-93.

5. Channer IL, Maclver AG. Glandular changes in the rete testis: metastatic tumour or adenomatous hyperplasia? J Pathol 1989; 157: 81-2.

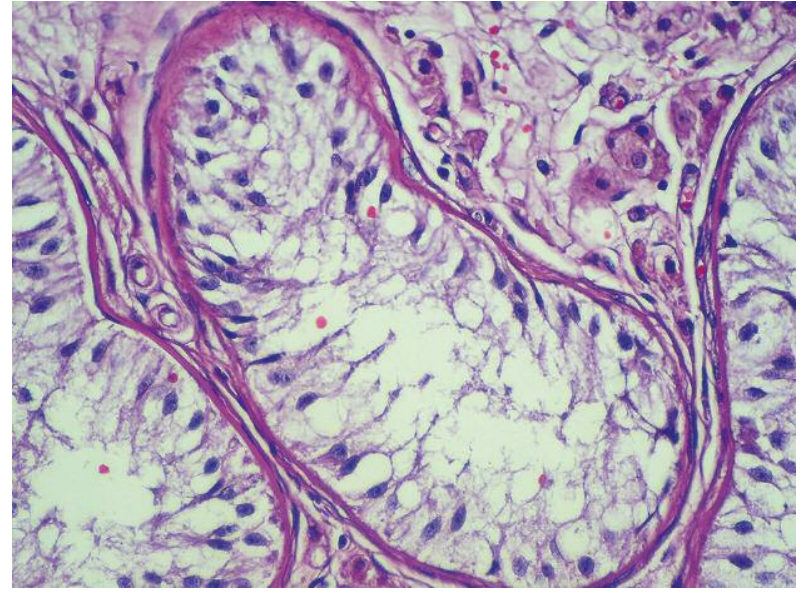

Fig. 2. Seminiferous tubules with no spermatozoa. HE, magnification $400 x$

6. Gruber R, Ratschek M, Pummer K, Breinl E, Spuller E, Hubmer G. Adenocarcinoma of the rete testis: a report of a case with surgical history of adenomatous hyperplasia of the rete testis. J Urol 1997; 158: 1525-26.

7. Lee AHS, Theaker JM. Pagetoid spread into the rete testis by testicular tumors. Histopathol 1994; 24: 385-89.

8. Warren R, Hartwick J, Ro JY, Srigley JR, Ordonez NG, Ayala AG. Adenomatous hyperplasia of the rete testis: a clinicopathologic study of nine cases. Am J Surg Pathol 1991; 15: 350-57.

\section{Address for correspondence}

Tumay Ozgur Assist. Prof. Department of Pathology

Mustafa Kemal University Medical Faculty

Serinyol-Hatay, 31120 Turkey

tel. +90 $5052293261,+903262277328$

fax +903262856020

e-mail: ozgurtumay@yahoo.com

Submitted: $\quad 24.02 .2012$

Accepted: $\quad 23.07 .2012$ 